DOI: $10.17805 / g g z .2017 .3 .3$

\title{
Классическая, неклассическая и постнеклассическая культуры: опыт новой типологии
}

\author{
А. Я. ФЛИЕР \\ РОССИЙСКИЙ НИИ КУЛЬТУРНОГО И ПРИРОДНОГО НАСЛЕДИЯ ИМЕНИ Д. С. ЛИХАЧЕВА
}

В статье предлагается новая типология культурь. Это позволяет рассмотреть исторические культурь как мировоззренческие системь и разделить их на типь по особенностям отношения к истине, добру и злу, предпочитаемым моделям соииального устроения и по другим основаниям. Ключевые слова: культура; классика; неклассические и постнеклассические культурь; мировоззрение; типология культур

\section{Classical, nonclassical and post-nonclassical culture: An attempt of a new typology}

\author{
A. Y. FLIER
}

D. S. LIKHACHEV RUSSIAN INSTITUTE OF CULTURAL AND NATURAL HERITAGE

The paper proposes a new typology of culture. This allows us to consider historical cultures as ideological systems and to divide them into types according to their specific relationship to truth, good and evil, the preferred models of social order and on any other grounds. Keywords: culture; classics; non-classical and post-non-classical culture; worldview; typology of cultures

В науке встречается множество названий культуры того или иного исторического периода. Часть из них не удерживается в профессиональном лексиконе, а некоторые становятся устойчивыми терминами со столь же устоявшимися значениями. К числу таких укоренившихся названий относится и словосочетание «классическая кульmypa».

Появление понятия «классическая культура», по всей видимости, следует отсчитывать от эпохи итальянского Возрождения (XV в.), когда так стали называть архитектуру и скульптуру Античности, служившие эстетическими образцами для художественных корифеев Возрождения (Вазари, 1933). В последующие четыре века понятие «классическая культура» серьезно расширилось в своем содержательном объеме. Вопервых, помимо архитектуры и искусства оно начало включать и другие проявления античной культуры - античную мифологию, философию и науку, литературу и драму, античную демократию, римское право и этос, античную государственную и воинскую символику, атрибутику, ритуалы и пр. Во-вторых, в это понятие постепенно стали включать всю европейскую аристократическую культуру Нового времени (в том числе и русскую, начиная с XVIII в.), ориентированную на воспроизводство античных форм, опять-таки не только в искусстве и архитектуре, но и в элементах социальной культуры высшего общества, стилизованных под античность (Винкельман, 2000), противопоставляя ее «темному средневековью».

B XIX в. в общественных вкусах произошла «реабилитация» европейского средневекового, византийского и древнерусского искусства. Хотя эти феномены не были включены напрямую в понятие «классическая культура», но фактическое отношение 
к ним и забота по их сохранению и воспроизводству ничем не отличалось от отношения к стилевой классике. Ну, и наконец, культуры Востока, в отношении которых появились специальные определения «классическая китайская культура», «классическая японская культура» и т. п. Иными словами, исторические культуры Востока дефакто были признаны классическими, хотя их никогда не объединяли с европейской стилевой классикой в одно явление.

Вместе с тем, нужно отметить, что традииионные народные культуры сельских жителей Европы и России в понятие «классическая культура» не включались. Но, если в Европе и России их стилевое отличие от элитарной культуры аристократии было очевидным, то о Востоке этого не скажешь. Произведения народной культуры здесь отличались от элитарных скорее мастерством исполнения, чем стилистикой. Вопрос об их типологизации до сих пор остается открытым.

Так или иначе, но понятие «классическая культура» существует в двух форматах - широком и узком. В широком формате классическая культура - это практически вся постпервобытная элитарная культура Евразии от сложения городских цивилизаций до промышленного переворота второй половины XIX в., а в узком - культура Античности и нововременная европейская городская культура, в той или иной мере воспроизводящая в своих формах античные образцы. Характерной чертой этой культуры (в обоих форматах) является ее императивная идеологичность, обусловленность определенной религиозной или политической идеологией, пропагандой которой эта культура занимается. Это культура-идеология (Флиер, 2015. Электронный ресурс) в наиболее чистом виде. При этом нужно помнить, что, во-первых, народная (традиционная) культура сельских жителей в категорию «классическая культура»не попадает, поскольку преследует свои специфические социальные цели, которые идеологичны латентно, а в основном ориентированы на мифоритуальный тип мировосприятия. И, во-вторых, классическая культура не ограничивается искусством и архитектурой, а включает в себя весь набор символических форм социально-бытового и военно-политического плана, маркирующих социальную престижность того или иного носителя, его принадлежность к аристократии, власти, наличия богатства, статуса или иной возможности своего социального выделения.

Главное, что отличает эту культуру, - это предельно четкое деление мира на добро и зло, хорошее и плохое, благостное и греховное, правильное и неправильное и т. п. Парность этих экзистенщиальных оппозищий с наибольшей ясностью выражена в религии (Бог-дьявол, праведное-греховное). Но и в любой сфере культуры присутствует сентенция «белое - это то, что не черное, а черное - это то, что не белое» (Григорьева, 1979). Такой тип сознания принято называть логочентрическим (Пелипенко, 2014). Считается, что он возник в ходе культурной трансформации «осевого времени» (IX-III вв. до н. э.) (Ясперс, 1991). В кристаллизованных формах, возможно, он социально возобладал именно в это время и чуть позднее, когда складывались основные религии, определившие дальнейшие судьбы мира. Но в зачаточном виде он, конечно, формировался еще с первых городских цивилизаций Египта, Месопотамии, Ирана и Индии (Франкфорт Г., Франкфорт Г. А., Уилсон, Якобсен, 1984).

Четкой аксиологической структурированности сознания сопутствовала и столь же четкая иерархичность воспринимаемого мира и социального устройства («воюющие - молящиеся - трудящиеся»). Истина в этой культуре была абсолютной и предустановленной. Задача человека заключалась лишь следовании ей и расширении своего знания о ней. Ааже научное знание в своих определяющих текстах было столь же 
четким и безусловным. Бытие - это поле битвы между добром и злом, истиной и ложью. Кто не с нами, тот против нас - еретик, грешник, иноверец и т.п. Классические культуры одарили человечество выдающимися образцами идеологии гуманизма и столь же выдающимися примерами жестокости по отношению к Аругому, к тому, кто трактует благо и истину иначе.

На обслуживании этой бинарной оппозиции в сознании людей, этой вечной битвы добра со злом, как их основной социальной практики, была сконцентрирована классическая культура. Эта ее функция особенно заметна по религиозным установкам и в искусстве. «Белое нужно для того, чтобы противостоять черному».

Художественные формы классической культуры, как правило, отличаются миметичностью (от греч. «мимесис» - подражание искусства действительности), стремлением к более или менее точному воспроизводству черт наблюдаемой реальности, т. е., говоря упрощенно, реализмом. Ааже когда воображение автора строит вымышленные миры, они все равно оказываются заполненными узнаваемыми земными формами. Например, $\Lambda$ уна в романе Фр. Бэкона в «Человек на $\Lambda$ уне, как и у С. Сирано де Бержерака в «Государствах и империях $\Lambda$ уны» оказывается заселена людьми, «Утопия» Т. Мора также воспроизводит земные реалии, в загробном мире «Божественной комедии» Аанте находятся известные исторические персонажи и т. п. То же можно сказать и об изображениях ада И. Босхом, богах и чудовищах в античной мифологии. 3десь все легко узнаваемо по своим земным формам. Мотивация деяний богов вполне человеческая. Европейский и китайский драконы - это огромные змеи с крыльями, а инфернальные чудовища средневековых художников - в основном гигантские насекомые. Все воспроизводит наблюдаемый мир. В этом суть художественного метода классической культуры: плоды воображения должны легко дешифровываться и узнаваться, благодаря своему подобию земной реальности. Художники и писатели классической эпохи редко изобретали новые образы, сюжетные ходы, социальные коллизии. Творческое соперничество в основном ограничивалось техническим качеством изображения канонических образов, интерпретацией канонических сюжетов.

В классической культуре дважды два всегда оказывается равно четырем, несмотря на сопротивление обстоятельств, добро всегда побеждает зло (хотя бы морально), а справедливость торжествует, поскольку истина абсолютна и никаким силам зла ее не преодолеть. Это культура по существу религиозная, даже когда она противоречит каким-то установкам той или иной конкретной религии. Но вера в абсолютность истины (осознанно или латентно божественной) и «естественную» иерархическую структуру мира все равно доминирует.

Особенно важна иерархичность осознаваемого мира. Она подразумевает наличие какого-то высшего авторитета (Бога, монарха, вождя), диктующего истину в последней инстанции. И вся классическая культура, так или иначе, пропагандирует подобные истины. Тем более, что никто не стремится проверить их обоснованность или абсолютность. Аюбое сомнение трактуется как измена и безжалостно наказывается. Поэтому в классической культуре так медленно развивалась рациональная наука, которая без сомнения в господствующих истинах по определению неэффективна. Однако в идеологических рамках господствующего мировоззрения классическая культура достигала выдающихся результатов, творила шедевры, которые навряд ли когда-нибудь будут превзойдены.

Вторую половину XIX в. принято рассматривать как начало научно-технического переворота в истории человечества. Впрочем, нас интересуют не технические изобре- 
тения, а трансформация восприятия и интерпретации мира в сознании людей. Начался этот поворот в науке, благодаря большому числу естественнонаучных открытий, но очень быстро отразился и в культуре. По аналогии с тем, что науку этого периода принято называть неклассической (Степин, 2000), мы полагаем, что и в культуре наступил неклассический период.

Своеобразной вершиной этого нового мировосприятия в науке стала теория относительности А. Эйнштейна, опубликованная в 1905 г. (специальная теория относительности) и в 1907-1916 гг. (общая теория относительности). Не вдаваясь в сложные физико-математические аспекты этой теории, отметим, что на культурное сознание того времени оказала наибольшее влияние идея контекстуальной зависимости любой истины (Айзексон, 2015). Ааже пространство и время представляют собой не независимые субстанции, а лишь продукт вселенского контекста, наблюдаемого взаиморасположения космических объектов, при изменении которого изменятся параметры пространства и времени. Соответственно и любая истина сохраняет свою верность лишь ситуативно, в определенных внешних условиях. Аважды два равняется четырем только в трехмерном пространстве, а при изменении мерности пространства результат будет иным.

Нельзя сказать, что в культуре очевидны следы непосредственного влияния идей Эйнштейна, но отказ от постулата абсолютности истины, так или иначе, несомненно, оказал свое воздействие на культурное сознание. Возвращаясь в рамках этого нового мироощущения к образу «белого и черного», можно сказать, что белое - это черное, увиденное в ином контексте, при иных внешних обстоятельствах.

Художестъенный авангард появился практически одновременно с теорией Эйнштейна. Их взаимосвязь представляется как очевидной, так и весьма опосредованной. Художники и писатели навряд ли читали научные труды по физике, но идеи Эйнштейна родились не на пустом месте. Новое мироощущение буквально «носилось в воздухе». Вопрос был лишь в том, кто и как его выразит. Беспредметная живопись, атональная музыка, театр абсурда и пр. творческие новации художественного авангарда явились латентными попытками выйти за пределы трехмерного ньютоновского пространства и посмотреть, чему будет равняться дважды два в другой системе измерений, при отмене абсолютности истины.

Вместе с тем, художественный авангард, отвергая формы классической культуры, сравнительно лояльно относился к классическим культурным содержаниям, не очень отдаляясь от них, хотя авторы соревновались в создании новых оригинальных образов, сюжетных ходов, панорамных ракурсов и т. п. Одной из главных творческих задач неклассической культуры стала разработка новых культурных фрорм, которые должны были прийти на смену классическим. Эти новые формы уже не были детерминированы соображениями миметичности, как неким идейным обязательством, и их оригинальность заслуживает специального обзора. Аля нас же существенно то, что новые формы отнюдь не вытеснили классические из культурного оборота, но существенно пополнили их банк, раздвинули рамки культурных ограничений допустимого и недопустимого.

Было бы ошибочным сводить всю неклассическую культуру к одному лишь художественному авангарду. Основная социальная задача, решавшаяся этой культурой, была связана с разрушением привычки общества к Вертикальному сословно-иерархическому устроению и внедрением привычки к устроению горизонтальному демократическому. Политически во многих странах Европы это было сделано еще в XIX в., но 
массовое социальное сознание менялось медленно. В большой мере внедрение демократического принципа равных стартовых возможностей было связано с распространением массовой культурь, родившейся в период активной урбанизации второй половины XIX в. Об эстетических достоинствах этого феномена можно спорить, но его социальные преимущества проявили себя быстро и с достаточной полнотой.

Проблема борьбы добра со злом не утратила своей принципиальной актуальности, но уже не было речи о той идеологической истерии, которая была свойственна прежним векам с их классической культурой. Опыты российского большевизма, итальянского и испанского фашизма и немецкого нацизма по возвращению к ажиотированной идеологичности политического и культурного устроения не встретили понимания в западных либерально-демократических обществах. Это были слишком откровенные попытки остановить историю.

В целом неклассическая культура, конечно же, была внерелигиозной (не зависимо от индивидуальной религиозности того или иного ее деятеля), поскольку отрицала абсолютность истины и наличие высшего авторитета, эту истину изрекающего. В числе главных социально-культурных достижений этой культуры следует перечислить торжество либеральной демократии, преодоление массовой неграмотности, разрушение классовых, расовых и национальных ограничений, радикальное расширение поля социальной самореализации женщин. Аостаточно проследить в течение XX в. внедрение общего начального, а затем и среднего образования, рост гуманитарной эрудированности широких слоев населения, благодаря книгам и кино, процесс демократизации городского костюма и этики поведения в публичных ситуациях и т. п. Именно в условиях торжества неклассической культуры научный концепт культурь превратился в один из основных объяснительных инструментов системного знания о социальных процессах, формирующих общественный организм.

В последней трети XX в. произошел еще один научно-технический переворот, оказавший существенное воздействие на культуру. Речь идет о радикальном рывке в развитии электронно-вычислительной техники и, в особенности, о внедрении в массовое пользование индивидуальных компьютеров, становлении Интернета и развитии социальных сетей. В культуре это привело к сложению новой дистанционной системы межличностной коммуникации, началу перехода от книжной к экранной культуре и подстегнуло процесс социального возобладания массовой культуры как основной культуры повседневности всего городского населения.

Одновременно в науке произошло становление новой исследовательской парадигмы, названной постнеклассической (Степин, 2000), наиболее характерным примером которой стала синергетика. Основная мировоззренческая новация новой парадигмы заключалась в признании того, что истина не является научной категорией, поскольку она заведомо субъективна и отражает ту или иную ангажированность ученого какой-то философской или политической идеологией (как правило, это ангажированность латентная, определяемая общим мировоззрением ученого как человека, гражданина и т. п.). Новое отношение к истине хорошо иллюстрируется анекдотом, в котором учитель спрашивает ученика, сколько будет дважды два, на что тот отвечает вопросом на вопрос: «А сколько Вам нужно, господин учитель?» Истина фактически зависит от того, «сколько нужно господину учителю». Возвращаясь к образному примеру «белое - черное», эту познавательную ситуацию можно охарактеризовать, сказав, что белое и черное - это субъективные интерпретации любого цвета разными авторами. Хотя рождение постнеклассической науки в основном связывается с синер- 
гетикой, это новое понимание истины выразилось более всего в культурно-философском течении постмодернизма, что дает нам основание этот новый этап в развитии культуры назвать постнеклассической культурой, по аналогии с наукой. Этот вопрос поднимала О. В. Архипова в своей докторской диссертации (Архипова, 2012), однако в связи с иными проблемами, рассматриваемыми в работе, он остался не раскрытым в интересующем нас аспекте. Впрочем, и синергетики считают случайность столь же важной и частотной, как и закономерность, что, естественно, ставит под вопрос значимость научной истины, случайной на $50 \%$.

Наиболее характерные черты новой культуры уже были описаны в специальной литературе (Ильин, 1996; Можейко, 1999; Маньковская, 2000), так что мы остановимся лишь на принципиальных отличиях постнеклассической культуры от классической и неклассической. В первую очередь нужно заметить, что, если неклассическая культура отвергала формы классической, но не возражала против ее культурных содержаний, то постнеклассическая, наоборот, вполне лояльна к формам, но отвергает культурные смысль прошлого. К историческим культурным формам постнеклассическая культура относится с ироничным покровительством, охотно используя их в своих парадоксальных концептуальных конструкциях и полагая, что все слова давно сказаны, все образы уже созданы, и задача современной культуры использовать их в различных интерпретациях. А вот культурные смыслы обусловлены контекстами, которые по ходу истории меняются, и сегодняшние обращения к древним контекстам, по меньшей мере, неактуальны. Нужно создавать современные контексты, помещая в них классические сюжеты. Наиболее известный пример такого подхода - кинофильм База Аурманна «Ромео и Ажульетта» с Аеонардо ди Каприо и Клэр Аейнс, действие которого перенесено в современную Америку. Опыты по современной режиссерской интерпретации классических опер также хорошо известны. Можно сделать вывод, что, если неклассическая культура была озабочена созданием новых форм, то постнеклассическая занимается в основном реинтерпретачией старых форм.

Постнеклассическая культура родилась не на пустом месте. В предшествовавшей ей неклассической культуре можно обнаружить явления, бывшие ее прямыми провозвестниками. Например, сюрреализм в литературе и живописи и в большой мере театр абсурда не экспериментировали с новыми формами, а помещали узнаваемые классические формы в парадоксальные контексты, т.е. фактически әкспериментировали со смыслами. Это были чисто художественные эксперименты, теоретическое основание которых появится позже в философии постмодернизма, но их уже можно назвать прото-постмодернизмом. Во всяком случае, литературное творчество Ааниила Хармса и роман М. А. Булгакова «Мастер и Маргарита» оцениваются как провозвестники постмодернизма (Руднев, 1999).

Широкой публике постнеклассическая культура известна в основном литературными и архитектурными произведениями, выражающими художественные принципы постмодернизма, экстравагантными постановками классических опер и такими эпатажными акциями, как, например, новосибирские «Монстрации», творчество арт-группы «Война», выходки «Pussy riot», женского движения «Femen» и т. п. Однако, представляется, что постнеклассическое направление войдет в историю культуры в первую очередь своими интеллектуальными поисками в области философии, гуманитарных наук, публицистики, переосмысливающими ярлыки добра и зла, хорошего и плохого, правильного и неправильного, накопившиеся за века господства классической культуры. 
Говорить о религиозных корнях постнеклассической культуры еще меньше оснований, чем искать какую-то религиозность в культуре неклассической. Проблема соперничества добра со злом воспринимается постнеклассической культурой тоже с иронией, поскольку ярлыки добра и зла раздают люди, преследующие какие-то свои интересы, что делает эти ярлыки заведомо спорными. Аобро может победить зло, если это «нужно господину учителю», сегодняшнему властителю умов. А завтра властителем умов станет другой учитель и все может перемениться. Знаменитый грибоедовский вопрос «А судьи кто?» может рассматриваться как лозунг постнеклассической культуры.

Однако не стоит рассматривать постнеклассическую культуру только в негативном ключе, как основной источник проблем современных последователей классической культуры. Эти проблемы обусловлены не экспансией постнеклассической культуры, а изменившимися социальными условиями жизни людей, их радикально возросшей информированностью, изменением демографического состава жителей больших городов и еще рядом новаций в социокультурных порядках, которые в совокупности понизили интерес массы населения к артефактам классической культуры до невиданного ранее уровня. Классическая культура остается актуальной для очень небольшой культурной элиты современных сообществ. В этих условиях постнеклассическая культура, если не возвращает массовый интерес, то, по крайней мере, способствует информированности населения об основных феноменах классической культуры, ее формах, сюжетах и пр. Неклассическая авангардная культура не делает и этого.

Сочиальную эффективность постнеклассической культуры, конечно, определять еще рано. Но в качестве тенденций, уже проявившихся к настоящему времени, можно перечислить:

- возрастающую независимость человека от государства,

- трудовую и образовательную мобильность,

- толерантность по отношению к отклонениям от социальных стандартов,

- переход от книжной к экранной культуре,

- растущее отчуждение от классической культуры.

В этот список можно было бы включить еще глобализацию и мультикультурацию, но еще не ясно, во-первых, влияет ли глобализация на культуру, а, если да, то как, и, во-вторых, является ли мультикультурация естественным процессом или это искусственный водоворот, инициированный политикой Евросоюза.

Так или иначе, но понятно, что сложение и функционирование каждого из рассмотренных типов культуры тесным образом связано с господствующем на каждом этапе истории мировоззрением, методом обобщения и аналитического упорядочения представлений о мире и социальном устроении - религией для классической культуры, наукой и философией для неклассической и постнеклассической культуры. В этот ряд в принципе можно включить и народную традиционную культуру в качестве «доклассической», сложившейся в условиях господства мифоритуального мировоззрения.

А вот, что касается мировоззренческой основы массовой культуры, то здесь, как представляется, господствует своеобразное «скольжение по поверхности» всех мировоззрений и ситуативное использование любых их элементов, что делает массовую культуру таким пластичным и конформным «мхом на рельефе» социального бытия. Вместе с тем, по своей непосредственной ситуативной социальной эффективности массовая культура превосходит все иные культурные феномены, являясь основной культурой повседневности современного городского образа жизни. 
Что дает эта новая типологизация культур по сравнению с существующими в науке? Прежде всего возможность рассмотреть исторические культуры как мировоззренческие системы и разделить их на типы по особенностям отношения к истине, добру и злу, предпочитаемым моделям социального устроения и пр. А это дает возможность более детально проанализировать мировоззренческий аспект культуры как совокупного способа упорядочивания коллективной жизни людей и их социального сознания, как системного взгляда на мир и определения места человека в нем.

\section{СПИСОК АИТЕРАТУРЫ}

Айзексон, У. (2015) Эйнштейн. Его жизнь и его Вселенная. М. : Corpus. 1020 с.

Архипова, О. В. (2012) Идеи образования в контексте постнеклассической культуры : автореф. Аис. ... А-ра филос. наук. СПб. : РГПУ им. Герцена. 49 с.

Вазари, А. (1933) Жизнеописания 12 наиболее знаменитых живописцев, ваятелей и зодчих. M. : Academia. 468 c.

Винкельман, И. И. (2000) История искусства древности. СПб. : Алетейя. 800 с.

Григорьева, Т. П. (1970) Японская художественная традиция. М. : Наука, Ин-т востоковедения. 368 с. $256 \mathrm{c}$.

Ильин, И. П. (1996) Постструктурализм, деконструктивизм, постмодернизм. М. : Интрада.

Можейко, М. А. (1999) Становление теории нелинейных динамик в современной культуре: сравнительный анализ синергетической и постмодернистской парадигмы. Минск : БГЭУ. 297 c.

Маньковская, Н. Б. (2000) Эстетика постмодернизма. СПб. : Алетейя. 347 с.

Руднев, В. П. (1999) Словарь культуры ХХ века. М. : Аграф. 384 с.

Пелипенко, А. А. (2014) Культура и смысл // Пелипенко, А. А. Избранные работы по теории культуры. М. : Согласие-Артем. 728 с.

Степин, В. С. (2000) Теоретическое знание (структура, историческая эволюция). М. : Прогресс-Традиция. 743 с.

Флиер, А. Я. (2015) Аобро и зло в культурно-историческом понимании // Информационный портал Знание. Понимание. Умение. № 3. URL: http://www.zpu-journal.ru/e-zpu/2015/3/Flier_GoodEvil/ (дата обращения: 15.02.2016).

Франкфорт, Г., Франкфорт, Г. А., Уилсон, Аж., Якобсен, Т. (1984) В преддверии философии. Ауховные искания древнего человека. М. : Прогресс. 238 с.

Ясперс, К. (1991) Смысл и назначение истории. М. : Политиздат. 527 с.

\section{REFERENCES}

Ajzekson, U. (2015) Ebjnshtejn. Ego zbizn' i ego Vselennaya. Moskow, Corpus. 1020 s. (In Russ.)

Arhipova, O. V. (2012) Idei obrazovaniya v kontekste postneklassicheskoj kul'tury : avtoref. dis. ... d-ra filos. nauk. Sankt-Peterburg, RGPU im. Gercena. 49 s. (In Russ.)

Vazari, D. (1933) Zhizneopisaniya 12 naibolee znamenityb zhivopiscev, vayatelej $i$ zodchib. Moskow, Academia. 468 s. (In Russ.)

Vinkel'man, I. I. (2000) Istoriya iskusstva drevnosti. Sankt-Peterburg, Aletejya. $800 \mathrm{s.}$

Grigor'eva, T. P. (1970) Yaponskaya budozhestvennaya tradiciya. Moskow, Nauka, In-t vostokovedeniya. 368 s. (In Russ.)

Il'in, I. P. (1996) Poststrukturalizm, dekonstruktivizm, postmodernizm. Moskow, Intrada. $256 \mathrm{s.}$ (In Russ.)

Mozhejko, M. A. (1999) Stanovlenie teorii nelinejnyb dinamik $v$ sovremennoj kul'ture: sravnitel'nyj analiz sinergeticheskoj $i$ postmodernistskoj paradigmy. Minsk, BGEHU. 297 s. (In Russ.) Russ.)

Man'kovskaya, N. B. (2000) Ebstetika postmodernizma. Sankt-Peterburg, Aletejya. 347 s. (In 
Rudnev, V. P. (1999) Slovar' kul' tury XX veka. Moskow, Agraf. $384 \mathrm{s.}$

Pelipenko, A. A. (2014) Kul'tura i smysl. In: Pelipenko, A. A. Izbrannye raboty po teorii kul' tury. Moskow, Soglasie-Artem. 728 s. (In Russ.)

Stepin, V. S. (2000) Teoreticheskoe znanie (struktura, istoricheskaya ebvolyuciya). Moskow, Progress-Tradiciya. 743 s. (In Russ.)

Flier, A. Ya. (2015) Dobro i zlo v kul'turno-istoricheskom ponimanii. Informacionnyj portal Znanie. Ponimanie. Umenie. No. 3 [online] Avaible at: http://www.zpu-journal.ru/ezpu/2015/3/Flier_Good-Evil/. (access date: 15.02.2016). (In Russ.)

Frankfort, G., Frankfort, G. A., Uilson, Dzh., Yakobsen, T. (1984) V preddverii filosofii. Dubovnye iskaniya drevnego cheloveka. Moskow, Progress. 238 s. (In Russ.)

Yaspers, K. (1991) Smysl i naznachenie istorii. Moskow, Politizdat. 527 s. (In Russ.)

Аата поступления: 01.06.2017 2.

Флиер Андрей Яковлевич - доктор философских наук, профессор, главный научный сотрудник Российского НИИ культурного и природного наследия им. А. С. Аихачева. Адрес: Россия, г. Москва, Берсеневская набережная, д. 20. Тел.:+7 (495) 686-13-19. Эл. адрес: : info@ heritage-institute.ru

Flier Andrei Yakovlevich, Doctor of Philosophy, professor, chief researcher of the D. S. Likhachev's Russian Institute of cultural and natural heritage. Postal address: 20 Bersenevskaya Naberezhnaya, Moscow, Russian Federation. Tel.: +7 (495) 686-13-19. E-mail: info@heritage-institute.ru

\section{Аля изтирования:}

Флиер А. Я. Классическая, неклассическая и постнеклассическая культуры: опыт новой типологии [Электронный ресурс] // Горизонты гуманитарного знания. 2017, № 3. URL: http:// journals. mosgu.ru/ggz/article/view/513 (дата обращения: дА.мм.гггг.). DOI: 10.17805/ ggz.2017.3.3 